\title{
AS REPRESENTAÇÕES DO VIRTUAL E DO NOSTÁLGICO NO EPISÓDIO "SAN JUNIPERO" (2016) DA ANTOLOGIA BLACK MIRROR
}

Fabrício Silva Parmindo

\section{Recebido em 21 fev 2021. Fabrício Silva Parmindo}

Aprovado em 01 abr 2021. Mestrando na Pós-Graduação do Instituto de História (2019), na área de História Cultural, pela Universidade Federal de Uberlândia.

http://lattes.cnpq.br/3414559304518983

https://orcid.org/0000-0003-1752-9122

Resumo: Este artigo tem por finalidade refletir sobre a forma como o sentimento de nostalgia e as tecnologias virtuais são representadas em uma produção audiovisual de ficção científica. Para compor tal análise, será utilizado o enredo do episódio "San Junipero" (2016), da série multiplataforma Black Mirror (2011-presente). Entendendo o gênero de ficção científica, em suas diversas formas de produção, como uma expressão da subjetividade em relação ao desenvolvimento tecnológico e o espaço-tempo (RÉGIS, 2005, p. 116), pretendemos voltar nosso olhar para essa produção, buscando pontuar questões políticas presentes nas representações do passado nostálgico e do futuro tecnológico no episódio. Sendo este um produto audiovisual concebido e veiculado pela produtora de conteúdo online Netflix, esse artigo terá como interesse compreender também a aproximação de "San Junipero" com outras 
produções da plataforma que tematizam a nostalgia, entendendo o episódio como uma peça para analisar as representações políticas desse tema nas mídias digitais de conteúdo sob demanda.

Palavras-chave: Nostalgia. Tecnologias virtuais. Netflix. Black Mirror.

Abstract: This article aims to reflect on the representations of nostalgia and the virtual technologies in a science fiction audiovisual production. To compose this analysis, we will use the plot of the episode "San Junipero" (2016), from the multiplatform series Black Mirror (2011-present). Understanding the science fiction genre, in its various forms of production, as an expression of subjectivity in relation to technological development and spacetime (RÉGIS, 2005, p. 116), we intend to turn our gaze to this production, seeking to punctuate political issues present in the representations of the nostalgic past and the technological future in the episode. As an audiovisual product designed and aired by the online content producer Netflix, this article will also be interested in understanding the approach of "San Junipero" and other productions of the platform that thematize the feeling of nostalgia, understanding the episode as a piece to analyze the political representations of this theme in the digital media of on-demand content.

Keywords: Nostalgia. Virtual technologies. Netflix. Black Mirror.

\section{INTRODUÇÃO}

Viagem temporal, máquinas capazes de lançar seres humanos no passado e no futuro, fantasias utópicas e distópicas sobre o que foi e sobre o que será a realidade das sociedades em um futuro próximo ou longínquo. O tema do tempo e seus mistérios são uma 
das principais faces da ficção científica. Em uma das obras canônicas do gênero, A Máquina do Tempo (1895), de H. G. Wells, a ruptura do tempo e do espaço é possibilitada por uma máquina complexa, criada com base em conceitos matemáticos, catapultando seus usuários em um passado selecionado cronologicamente. Trata-se da primeira obra literária do gênero a trabalhar com este tema que seria, durante todo o século XX e no início do século XXI, uma fonte de inspiração imaginativa, apropriada e reinterpretada em diferentes contextos. De autoras como Ursula Le Guinn e Octavia Butler na literatura, a produções televisivas como Além da Imaginação (1959) e Jornada nas Estrelas (1962) e produções cinematográficas como nas trilogias De Volta para o Futuro (1985) e Matrix (1999), o tema das viagens temporais foi e continua sendo uma fonte de inspiração para os enredos fantásticos ou trágicos da ficção científica.

Nestes diferentes contextos, a prevalência de narrativas sobre viagens temporais, dentre outros temas característicos do gênero tais como o conflito entre natureza e máquina, humanidade e tecnologia e indistinção da fronteira entre o real e o artificial, compõem as bases narrativas que identificam o gênero de ficção científica. Estes temas, que podem se aglutinar numa mesma narrativa, longe de pertencerem ao campo do irreal e do impossível, estão ancorados em imaginários compartilhados social e culturalmente por sociedades que convivem com os produtos tecnológicos, com o pensamento científico e com a racionalidade moderna. Como apontado por Fátima Régis, em sua análise sobre a relação entre a ficção científica e a sociedade,

enquanto pensadores e cientistas buscam as condições de concretização da Utopia Moderna 
por meio da antecipação do futuro, os escritores de ficção científica narram as outras utopias, distopias e heterotopias possibilitadas pelo entrelaçamento entre subjetividade, tecnociência e outras configurações de espaço e tempo. (RÉGIS, 2005, p. 116)

Em outras palavras, a ficção científica tornou-se um gênero que lida com as contradições, os benefícios, as expectativas e os anseios consequentes das inúmeras possibilidades inauguradas pelo avanço científico e pela ideia de progresso na modernidade.

Feitos estes apontamentos, o recorte que pretendemos realizar na análise do episódio "San Junipero" e da série Black Mirror, utiliza do tema do espaço-tempo e da presença das tecnologias do ponto de vista de seu uso para acessar o passado. Na construção visual e no enredo de "San Junipero", o tema do espaço-tempo ancora-se no desenvolvimento das tecnologias virtuais, tendo como mote dramático as suas consequências e compreensões pela sociedade na qual se insere. Nesse sentido, a trama do episódio se apropria de diferentes temas do gênero para questionar os usos e abusos da tecnologia, bem como repensar os sentidos da nostalgia na sociedade em que se insere.

Na série Black Mirror, cujos episódios possuem narrativas independentes, mas que compartilham um mesmo escopo crítico, o espectador acompanha diferentes perspectivas em relação às tecnologias de informação e comunicação. Os diversos cenários propostos pela série abordam desde personagens que resistem ao uso das tecnologias, a protagonistas que moldam suas vidas a partir da imagem que constroem nas redes sociais, passando por tramas sobre as dificuldades causadas pela potencialização da vigilância 
dos aparelhos digitais, entre outros temas. O escopo da série, de modo geral, reflete sobre e questiona o uso das tecnologias neste contexto tecnológico vertiginoso e em constante aceleração na segunda década do século XXI.

O episódio "San Junipero" é um fragmento da terceira temporada da antologia Black Mirror, sendo o quarto episódio desta que foi a primeira temporada a ser transmitida exclusivamente pela plataforma de streaming ${ }^{1}$ da empresa estadunidense Netflix. A Netflix foi pioneira na consolidação comercial das plataformas de streaming e no estabelecimento deste novo formato de consumo audiovisual. Com 195 milhões de assinantes em todo mundo e dezenas de filmes e séries produzidas originalmente, a empresa se tornou a principal indústria do ramo, com diferentes indicações a grandes premiações do audiovisual. Sua principal inovação foi a popularização do conceito de "maratonar" séries e filmes, além de inaugurar um modelo que fora apropriado e replicado por outras grandes companhias globais como os canais CBS, HBO e Disney Company, e empresas fora do ramo audiovisual, como a Amazon².

A antologia, de modo geral, desde suas primeiras temporadas transmitidas no Reino Unido pelo Channel 4, à sua adaptação para a plataforma digital estadunidense, se tornou uma referência de

1 Uma plataforma de streaming é uma tecnologia de transmissão de dados comumente empregada para transmitir e distribuir conteúdo multimídia e produções audiovisuais pela internet. Os conteúdos são acessados por assinaturas pagas, possuindo um catálogo de produções compradas, originais e localizadas conforme o país, oferece estruturas multimidiáticas para os usuários e permite consumir produções e catálogos distintos em smartphones, tablets, notebooks e aparelhos de televisão com acesso à internet.

2 Para um maior aprofundamento sobre o consumo audiovisual nas plataformas de streaming, ler mais em: SILVA, Marcel Vieira Barreto. Cultura das séries: forma, contexto e consumo de ficção seriada na contemporaneidade. Galáxia (São Paulo), São Paulo, v. 14, n. 27, p. 241-252, junho de 2014. Disponível em: http://dx.doi.org/10.1590/198225542014115810. Acesso em: 8 de fev. 2021. 
produção audiovisual que expressa, em suas diferentes tramas, as expectativas e anseios voltados para o uso das tecnologias de interação e comunicação no presente. Assim sendo, o presente trabalho tem o intuito de investigar o episódio "San Junipero" a partir do contexto e das condições na qual o episódio foi produzido, veiculado e consumido, considerando as questões pertinentes em sua composição para a compreensão da relação entre as tecnologias virtuais e os sentidos políticos e culturais da nostalgia. Para tal, propomos uma análise sobre o enredo e os argumentos narrativos do episódio, a fim de discutir sobre a forma com que a produção constrói e representa a atmosfera nostálgica e tecnológica em sua trama.

\section{A VIRTUALIZAÇÃO DA SOCIEDADE PELO OLHAR DA FICÇÃO CIENTÍFICA}

No episódio "San Junipero", dirigido por Owen Harris e roteirizado por Charlie Brooker, criador original da série, acompanhamos o drama de Yorkie em sua busca por reviver sua juventude dentro do sistema de realidade virtual denominado San Junipero. Yorkie, uma jovem tímida e introvertida, se apresenta como a personagem que guia o espectador na revelação da realidade virtual do sistema, conduzindo-nos a conhecer a ambientação nostálgica da cidade litorânea que leva o nome da tecnologia em questão. O episódio inicia com as primeiras impressões de Yorkie em relação a uma realidade aparentemente situada no ano de 1987: a canção "Heaven Is a Place On Earth" (1986), de Berlinda Carlisle é ouvida por jovens que estacionam a frente de um bar, trajando coletes jeans e cabelos volumosos, 
em uma rua repleta de neons, carros antigos e propagandas de produtos lançados neste ano específico.

Revivendo sua juventude na cidade de San Junipero, a jovem tímida conhece Kelly, uma jovem negra e extrovertida, por quem Yorkie se apaixona. Kelly, diferente de Yorkie, já é conhecida em San Junipero, tendo tido alguns casos com outras pessoas da cidade. A partir do momento que as duas personagens se conhecem, a trama é conduzida pela paixão contida e receosa de Yorkie por Kelly. Enquanto Yorkie gostaria de viver um romance com Kelly, a jovem negra quer apenas curtir a vida de forma despretensiosa na cidade, no que ela define como "uma cidade de festas".

Até o minuto 38 do episódio, não é revelado ao público que toda a ambientação daquela trama está acontecendo no interior de uma tecnologia virtual. No momento de virada dramática, uma das principais características das narrativas de Black Mirror, o espectador descobre que toda aquela construção nostálgica está sendo programada no sistema chamado San Junipero, situado em um futuro próximo e sem identificação cronológica. A tecnologia criada pela empresa fictícia TCKR, com sede em Santa Rosa na Califórnia, garante aos seus usuários um "upload"3 mental em um conglomerado de computadores capazes de simular corpos virtualizados. O sistema funciona como uma "nuvem" de consciências convertidas em avatares que replicam as pessoas dentro deste espaço virtual.

Segundo a definição dada por Kelly, o sistema San Junipero funciona com finalidades terapêuticas, uma "terapia de imersão

3 O termo upload é utilizado na informática para definir o envio de dados externos para um servidor ou para a internet. 
nostálgica" na qual o usuário pode experimentar, individual e coletivamente, um ambiente nostálgico pré-programado. Aos usuários "visitantes", é oferecido uma experiência limitada, de apenas algumas horas por semana, e que se encerra à meianoite como um feitiço de conto de fadas. Aos usuários que fazem a "passagem", ou seja, que usam o sistema como uma vida após a morte, é oferecida uma experiência integral a esses que são chamados "full timer" na narrativa do episódio.

Apesar de compartilhar as experiências no mesmo sistema, as protagonistas possuem diferentes motivações em seu uso. Neste futuro próximo e não-identificado, Kelly, uma idosa com idade por volta dos setenta anos, visita o sistema San Junipero toda semana com fins terapêuticos, para se recuperar psicologicamente do tratamento de um câncer, reexperimentar a juventude, mas sem almejar viver eternamente no sistema. Já Yorkie, uma idosa com aproximadamente sessenta anos, se utiliza do sistema para conseguir viver sua vida perdida, uma vez que se encontra em coma desde os vinte e um anos. Após uma briga com sua família conservadora, que não aceitava sua homossexualidade, Yorkie se acidentou com um carro, deixando-a em coma por quarenta anos. Sua motivação em relação ao sistema é garantir uma eutanásia que permita a "passagem" de forma integral para San Junipero, para assim conseguir reviver sua juventude nesse cenário nostálgico.

O nome San Junipero faz referência às cidades situadas no estado da Califórnia, como San Francisco e San Diego. A referência não se limita somente aos nomes, mas à colonização da região oeste dos Estados Unidos que outrora pertencera à Coroa Espanhola na região da Alta Califórnia. A trama do episódio soma o argumento 
tecnológico a um pano de fundo histórico e religioso pela alusão ao frade jesuíta Junípero Serra (1713-1784), pertencente à Ordem Franciscana da Igreja Católica e considerado um dos "pais fundadores" da ocupação do oeste do país.

Esse pano de fundo histórico e religioso não é tratado de forma explícita na trama, mas contribui para a análise das representações do episódio. No quesito religioso, o sistema San Junipero seculariza os objetivos de conversão da alma das missões jesuítas do século XVII, tornando o "paraíso" cristão um lugar terreno e possibilitado pelas tecnologias virtuais do século XXI. No âmbito histórico, a referência ao oeste dos Estados Unidos não é por acaso, uma vez que a região foi o palco das principais revoluções tecnológicas ocorridas na segunda metade do século $X X$, especialmente na região do Vale do Silício ao norte da Califórnia.

Com essa revolução tecnológica, o território dos Estados Unidos se tornou também o palco das novas utopias e distopias da ficção científica. Outrora geograficamente identificada com a Revolução Industrial do século XIX na Europa, as transformações políticas e econômicas do século XX redirecionaram as narrativas do gênero às consequências das revoluções tecnológicas e sociais que despontaram no país em seu polo industrial californiano. Como analisado pelo sociólogo espanhol Manuel Castells, "se a primeira Revolução Industrial foi britânica, a primeira revolução da tecnologia da informação foi norte-americana, com tendência californiana" (2005, p. 70).

A Califórnia é um espaço geográfico importante também para o gênero de ficção científica. Como nos indica o historiador 
britânico Edward James, em Science Fiction in the Twentieth Century (1994), a "vitória" da ficção científica estadunidense foi apenas uma das facetas da hegemonia cultural do país no mundo, uma vez que futuro do século XX cada vez mais parecia se tornar "americano" (JAMES, 1994, p. 55). Esse futuro de alta tecnologia "americanizado", que hoje constitui nosso presente, se consolidaria pelas revoluções tecnológicas do oeste dos Estados Unidos provindas de empresas de tecnologia do "Vale do Silício", como a Apple Computers, a Microsoft, a Google, Intel e até mesmo a própria Netflix, cuja sede principal se encontra em Los Gatos, no estado da Califórnia.

Essa referência à Califórnia no episódio, analisada junto às outras tramas da terceira temporada, nos indicam uma nova identidade à série de Charlie Brooker em sua transposição para a plataforma de streaming. Apesar de ser uma produção originalmente britânica e televisiva, ao fazer alusão à história da Califórnia como o palco das narrativas de ficção científica, Black Mirror migra seu foco narrativo da Europa para os Estados Unidos, atentando-se a essas transformações ocorridas no gênero e adaptando suas tramas aos consumidores estadunidenses da plataforma da Netflix.

De volta à cidade de San Junipero. A ambientação nostálgica e todo o cenário retrô do episódio, conduzem o espectador a uma experiência de quebra de expectativas em relação às narrativas de Black Mirror. Os cenários futuristas, distópicos e os desfechos trágicos previamente explorados pela antologia, dão lugar a uma ambientação ao mesmo tempo futurista, tecnológica e sentimental, em um conflito amoroso semelhante a um filme romântico e teen da década de 1980. 
Essa associação da trama com a década de 1980, contudo, não condiz com a ideia de uma reprodução fiel dos "Anos 80 " tal como este foi vivido historicamente, mas ao sentimento nostálgico deixado por essa década e como ela é vista pelo presente do ano de 2016. Assim como as projeções futuristas da ficção científica, que dialogam com as expectativas do presente na qual são elaboradas em detrimento de uma capacidade profética de seus idealizadores, o passado representado em "San Junipero", que tem a memória viva dos "Anos 80" como norte, está associado à forma com que o presente enxerga esse passado.

Esta capacidade da ficção científica de fantasiar as infinitas possibilidades e expectativas do tempo futuro, podem ser associadas a uma forma particular de compreender e experienciar o tempo histórico, como analisado por Fredric Jameson (1982) em suas considerações sobre $\mathrm{o}$ gênero literário. $\mathrm{O}$ que distingue o gênero de ficção científica em sua forma e conteúdo não são as tentativas de imaginar o futuro de nossas sociedades de forma fiel. Jameson atribui ao gênero a capacidade de transformar o "nosso próprio presente no passado determinado de algo que ainda está para vir" (1982, p. 152, tradução livre $\left.{ }^{4}\right)$. Assim, se fosse possível atribuir uma característica intrínseca às representações futuristas do gênero, esta seria a capacidade de manter o futuro em constante reinterpretação, dramatizando nossa "incapacidade de imaginar o futuro" (1982, p. 153, tradução livre $\left.{ }^{5}\right)$.

4 No original: "Rather, its multiple mock futures serve the quite different function of transforming our own present into the determinate past of something yet to come."

5 No original: "On the contrary, its deepest vocation is over and over again to demonstrate and to dramatize our incapacity to imagine the future [...]." 
Pelas representações da ficção científica, os cenários futuristas e viagens temporais para o passado não conseguem mascarar sua representação do tempo presente, que se encontra contido na experiência e na identificação por parte de quem o consome em suas diversas formas, seja na literatura ou nas produções audiovisuais. Assim sendo, o tripé narrativo que une a subjetividade, a tecnociência e as diferentes configurações de espaço-tempo, como proposto por Régis (2002), sustentam essa forma de refletir sobre o próprio tempo pelo olhar da ficção científica.

Em "San Junipero", a representação deste futuro próximo se associa às expectativas presentes em relação ao devir das tecnologias de realidade virtual e suas potencialidades. O tema da "passagem" de Yorkie para uma vida eterna no sistema e sua tentativa de convencer Kelly a fazer o mesmo, situa as protagonistas em um conflito entre o que é permitido e limitado dentro e fora da virtualidade. Essa temática que pauta a oposição entre o "real" e o "virtual", que fora amplamente explorada na ficção científica na virada do século $X X$ e início do século $X X I$, também aproxima o gênero de ficção científica em relação a estudos literários, filosóficos e sociológicos interessados na expansão do consumo de tecnologias virtuais.

Para melhor conceituar nossa análise sobre esse tema, podemos destacar as propostas de compreensão da virtualização elaboradas pelo sociólogo francês Pierre Lévy na década de 1990. Buscando compreender as transformações sociais decorrentes da popularização das tecnologias de informação e das plataformas virtuais, Lévy atribui a esse fenômeno social e cultural de expansão da virtualidade, a ideia de uma "dinâmica" de virtualização, 
caracterizada pela desterritorialização de categorias outrora limitadas por estruturas tradicionalmente estabelecidas (LÉVY, 1996, p. 58).

É possível exemplificar essa "dinâmica" pela virtualização dos espaços de trabalho, que tendem a substituir a presença física dos empregados pela ampliação de sua participação nas redes de comunicação eletrônica. Para o pensador, essa "dinâmica" se difundiu junto ao consumo e a popularização das tecnologias interconectadas e do uso da internet, que estaria atingindo "as modalidades do estar junto, a constituição do nós" (LÉVY, 1996, p. 11), na expansão das comunidades virtuais, das empresas virtuais e até mesmo na idealização de uma democracia virtual. O pensador define que a "maneira de ser" dessa dinâmica se caracteriza não pelo aprisionamento e substituição da realidade pelo virtual, mas pela "mutação de identidade, um deslocamento do centro de gravidade ontológico do objeto considerado" (LÉVY, 1996, p. 17). Em outros termos, a virtualização de uma entidade qualquer garante a esta uma nova identidade e, como consequência, novas problemáticas.

No âmbito do trabalho, por exemplo, surgem questões tais como a necessidade de repensar os direitos trabalhistas para a realidade do "teletrabalho", conceituar as novas estruturas de trabalho inauguradas pela expansão das tecnologias de informação e comunicação (TICs), a ascensão de uma classe de "proletários de serviços" (ANTUNES, 2018) e o problema da indistinção do espaço privado do empregado em relação ao espaço compartilhado do trabalho. 
Mas a expansão da virtualização e suas consequências não se limita apenas ao espaço de trabalho. O incômodo causado pelos dramas e pelos cenários de Black Mirror, está associado às interrogações e representações feitas pela série em relação às consequências da virtualização de diferentes aspectos da vida cotidiana. De tecnologias que influenciam negativamente das relações amorosas, às ambientações distópicas altamente tecnológicas, a série se tornou um símbolo da ficção científica que tem como mote a crítica aos usos e abusos das tecnologias de comunicação cotidianas e populares do século $\mathrm{XXI}$, como smartphones, videogames, realidades virtuais e redes sociais.

O drama de Yorkie e Kelly em "San Junipero" está associado ao temor do que uma eternidade vivida em uma realidade virtual hipoteticamente ampla e complexa tem a oferecer e a subtrair. Isso se evidencia com mais clareza no drama de Kelly, cuja "passagem" para San Junipero representaria o fim de um trato que havia selado com seu marido já falecido Richard. Kelly e Richard possuíam uma história amorosa, uma filha, Alisson, também falecida, e um romance de mais de quarenta anos. Kelly afirma que Richard e Alisson optaram por não fazer a "passagem" para o sistema, nem ao menos experimentar, uma vez que isso ia contra suas crenças pessoais e religiosas. Kelly teria prometido a Richard que não se submeteria a essa "passagem". Mas a personagem acaba por buscar, devido ao seu câncer, uma alternativa para reviver a primavera de sua vida em San Junipero e, especialmente, conseguir se abrir para sua bissexualidade que não era aceita quando era jovem.

Yorkie se apropria da tecnologia com uma finalidade semelhante. Em coma desde os vinte e um anos, um trauma 
pessoal que carregou apenas por revelar sua homossexualidade, a personagem encontra na cidade de San Junipero uma possibilidade de viver a vida que não teve. Dentro do sistema San Junipero, a personagem elimina seus traumas e pode viver em um ambiente livre de preconceitos. Porém, diferente de Kelly, Yorkie não hesita em realizar a eutanásia que garante sua "passagem" para o sistema, uma vez que suas escolhas não possuem a mesma carga emocional que para Kelly.

Portanto, semelhante às proposições de Lévy em relação à expansão da virtualidade, a construção do argumento tecnológico do sistema San Junipero se ancora na concepção de uma nova identidade concedida à nostalgia pelas tecnologias virtuais. A virtualidade seria capaz de oferecer aos usuários uma experiência de "viagem temporal sentimental", por meio das imagens e dos sons que alcançam o presente carregados do sentimento da nostalgia. Portanto, o sistema seria capaz de "fazer do paraíso um lugar na Terra", como cantado na letra do principal tema do casal protagonista, "Heaven Is a Place on Earth" (1986).

Apesar de aparentemente ser um episódio com um distanciamento temporal mais longo em relação a outros episódios, as representações da tecnologia que servem ao argumento da trama de Charlie Brooker fazem alusão a conceitos tecnológicos presentes. Através de um pequeno aparelho conectado na lateral do rosto dos usuários, a consciência seria acessada, convertida e armazenada por um sistema semelhante à "nuvem de informação", utilizada amplamente pelas tecnologias de informação e comunicação atuais. Segundo a definição do Instituto Nacional de Padrões e Tecnologia dos Estados Unidos (NIST), a "computação em nuvem" é: 
[...] um modelo para permitir o acesso a uma rede ubíqua, prática e sob demanda, para um conjunto compartilhado de recursos computacionais (por exemplo, redes, servidores, armazenamento, aplicativos e serviços) que pode ser provisionado e liberado rapidamente com mínimo esforço de gerenciamento ou interação do provedor de serviços. (MELL; GRANCE, 2011, p. 2, tradução livre ${ }^{6}$ )

Em termos comuns, os serviços de computação em nuvem permitem uma forma eficaz de armazenamento que pode ser acessada à distância, sem a necessidade da existência de uma mídia física. No episódio, a menção ao conceito de "nuvem" é feita por Kelly, que de forma irônica, associa o termo tecnológico à crença religiosa da ascensão para o paraíso: Uploaded to the cloud. Sounds like heaven!, que poderia ser traduzido como "Subir para as nuvens. Soa como o paraíso!".

Outra representação possível de ser pensada a partir do argumento do episódio, está na ideia de memória coletiva e a consequente virtualização do passado. A ideia de perpetuação da informação, proporcionada pelo armazenamento interno das tecnologias digitais, acompanha o desenvolvimento exponencial da capacidade de arquivar dados de modo geral. Conforme analisado por Lévy, as tecnologias de informação caminham quase sempre no sentido de "uma maior capacidade de armazenamento, maior miniaturização, maior rapidez de acesso e confiabilidade, enquanto seu custo cai constantemente" (LÉVY, 1999, p. 32). Dessa capacidade, a busca pela digitalização e a virtualização da

6 Traduzido do original: "Cloud computing is a model for enabling ubiquitous, convenient, on-demand, network acess to a shared pool of configurable computing resources (e.g., networks, servers, storage, applications, and services) that can be rapidly provisioned and released with minimal management effort or service provider." 
memória como tentativa de perpetuação do passado, torna a memória acessível e quase infinita. Tendo como exemplo o maior arquivo digital existente, o Wayback Machine, organizado pela Internet Archive e no ar desde 1996, a expansão da capacidade de armazenamento permite que todo site criado seja indexado ao arquivo, que já possui 475 bilhões de páginas da web.

Em relação à sensibilidade do tempo e do espaço, Lévy identifica que a "dinâmica de virtualização" remodelou a compreensão clássica destas duas categorias, "tomando as tangentes" das referências geográficas e temporais. A virtualização estabelece uma temporalidade própria que, por mais dependente de estruturas físicas que não são capazes de existirem fora da referência compartilhada de espaço-tempo, se reorganiza de forma simultânea e ubíqua. Essa temporalidade consequente da virtualização, para Lévy, coloca as unidades de tempo e espaço à prova. Nas palavras do pensador,

a virtualização submete a narrativa clássica a uma prova rude: unidade de tempo sem unidade de lugar (graças às interações em tempo real por redes eletrônicas, às transmissões ao vivo, aos sistemas de telepresença), continuidade de ação apesar de uma duração descontínua (como na comunicação por secretária eletrônica ou por correio eletrônico). A sincronização substitui a unidade de lugar, e a interconexão, a unidade de tempo. (LÉVY, 1996, p. 21)

Dessa característica, o autor examina o surgimento de novos espaços de compartilhamento de informações e novas temporalidades de comunicação, consequentes da virtualização do texto, do corpo, da economia e de outras áreas. 
Essa "prova rude" que a virtualização impõe a compreensão do espaço-tempo no uso das tecnologias virtuais, é a base do sistema San Junipero e sua "viagem temporal" repaginada para a realidade tecnológica do século XXI. As consciências convertidas para o sistema estariam, nesse sentido, ancoradas no que Lévy atribui à "não-presença" desterritorializada, generalizada e veloz da informação virtual (LÉVY, 1996, p. 21). No interior daquele mundo virtualizado, o tempo e o espaço são desacoplados do entendimento compartilhado de linearidade temporal e de territorialidade do espaço, permitindo criar uma cidade fictícia e uma organização temporal artificial.

O sistema fantasiado e tornado o argumento tecnológico do episódio, representa não somente a transformação do espaço-tempo no interior das tecnologias virtuais, mas as novas identidades dadas às memórias, as vivências, os sentimentos, os corpos, os tempos passado, presente, futuro e a morte. Essas identidades possibilitadas pela virtualização, como nos aponta Lévy, longe de negar o "real", o complementa. Kelly, em alguns de seus diálogos com Yorkie, ironiza determinadas experiências "desrealizantes" no interior do sistema, como as reproduções dos estilos dos "Anos 80 " parecerem artificiais demais ou a forma com que os cigarros não possuem sabor na cidade de San Junipero. Contudo, a abordagem central da trama não procura se alinhar a uma crítica que reaja temerosamente a expansão do virtual como uma inevitável substituição total da realidade pelas máquinas, como outrora criticado pela perspectiva catastrófica de Jean Baudrillard sobre a virtualização ou pelas imagens da ficção científica em Matrix (1999). 
Tendo isso em vista, podemos atribuir a "San Junipero", bem como à antologia Black Mirror como um todo, a crítica voltada para a expansão das tecnologias de informação e comunicação que transformam e dão novas identidades aos diferentes aspectos da convivência em sociedade. Longe de anular ou substituir o "real" pelo "virtual", o episódio e as tramas apresentadas na antologia projetam futuros nos quais a ubiquidade dessas tecnologias não são representadas como fenômenos alheios ao mundo "real", mas "imaginadas, fabricadas e reinterpretadas" (LÉVY, 1999, p. 18) conforme o seu uso em sociedade.

O episódio "San Junipero" busca explorar outras abordagens possíveis entre a subjetividade, o desenvolvimento tecnocientífico e as novas configurações de espaço-tempo. Isso se evidencia no conflito entre as protagonistas, cujo mote se desenrola a partir do dilema de Kelly em relação à adesão ao sistema. A personagem, em diferentes momentos do episódio, indica sua intenção de uso exclusivamente terapêutico e passageiro do sistema, ao dizer que vivia San Junipero apenas como uma "curtição". Recusar a oferta da "passagem" para o sistema e morrer naturalmente, ou aderir à possibilidade de viver eternamente e virtualmente com Yorkie, indo contra suas crenças religiosas e sua promessa, compõem as adversidades da tecnologia para a personagem. Diferente de Kelly, o drama pessoal de Yorkie e sua família justificam a motivação da personagem em desejar viver eternamente em San Junipero. Encontrando no sistema uma possibilidade de experienciar sua juventude subtraída pelo coma, o dilema entre o "real" e o "virtual" é deixado de lado. O sistema San Junipero e os diferentes usos pelas protagonistas, nesse sentido, apontam para as ambivalências das 
condições oferecidas pelo sistema ao espectador, para além de conduzir-nos a conclusões dicotômicas entre os benefícios e os malefícios da tecnologia.

Essa construção narrativa do episódio reelabora alguns "lugares comuns" existentes no gênero de ficção científica. As representações feitas das subjetividades e dos imaginários que orbitam o desenvolvimento técnico-científico, comumente se sustentam em duas perspectivas opostas. Na análise lida em Combater o Futuro: Um olhar sobre as representações "tecnofóbicas" de ciência e tecnologia na cinematografia moderna (2009), Paulo Furtado se ancora nos conceitos sociológicos de "tecnofobia" e "tecnofilia" para compreender a ficção científica moderna. O autor nos indica que, por um lado, do ponto de vista da "tecnofilia", as transformações tecnológicas são entendidas e representadas como um sinal de progresso, uma salvação terrena para a humanidade garantida pela racionalidade moderna. Por outro, a "tecnofobia" representada em diferentes obras literárias e produções audiovisuais do gênero de ficção científica, percebe - avanço científico como a condenação das sociedades ao aprisionamento, a dependência, a substituição, a submissão e ao conflito entre máquinas e humanos (FURTADO, 2009).

Na história da ficção científica, a representação do "impacto" negativo causado pelas tecnologias, se tornou uma das principais características das narrativas do gênero. Como nos aponta Furtado, o gênero contribuiu para a popularização das visões "tecnofóbicas" da sociedade. Na ficção, com a popularização das tecnologias virtuais a partir da década de 1980, as expectativas em relação a expansão da "dinâmica de virtualização" alertavam para 
a possibilidade de um aprisionamento do "real" pelo "virtual". Para produções de ficção científica preocupadas com o tema, como a obra literária Neuromancer (1984) de William Gibson ou pela trilogia cinematográfica Matrix (1999-2003), a humanidade, a sociedade e os idealizadores dessa "nova era" tecnológica "não passam eles próprios de máquinas, presas numa gaiola digital, sem hipótese de fuga" (FURTADO, 2009).

O tema dos espaços virtuais, em "San Junipero", como destacado anteriormente, foge dessa perspectiva de conflito entre o "real" e o "virtual", ao mesmo tempo que busca alternativas à dicotomia representada pela "tecnofobia" versus a "tecnofilia". A tecnologia San Junipero, e seu uso terapêutico de imersão nostálgica, se configura como um produto de natureza ambivalente, facultativa e com diferentes possibilidades de uso. Para Yorkie, o sistema representa uma nova chance à sua vida traumática. Para Kelly, que aceita utilizar esporadicamente o sistema com fins terapêuticos, o remédio concedido pela tecnologia tem potencial para se tornar um veneno, uma vez que uma vida eterna em San Junipero não é vista como um ideal pela personagem, assim como não o era ao seu marido e sua filha falecidos.

Nesse sentido, a construção ambivalente do argumento tecnológico do episódio nos aponta para uma tentativa de superação das perspectivas dicotômicas características do gênero de ficção científica. Uma vez que o escopo crítico da série procura denunciar determinadas questões políticas e sociais advindas dos usos e abusos das tecnologias contemporâneas, a trama de "San Junipero" promove, aos espectadores, um olhar sobre o potencial 
da expansão da virtualização em sociedade. Nesse caso, o episódio enuncia as possibilidades imagináveis da forma com que a "dinâmica de virtualização" oferece novas identidades a temas como a nostalgia, as crenças religiosas e a morte, e como estas podem ser transformadas pelas tecnologias virtuais.

\section{A NOSTALGIA NAS TELAS: UM ANTÍDOTO AO PRESENTE}

O tema das tecnologias virtuais, o futuro indeterminado na trama e as ambientações futuristas que nos remetem às imagens construídas pela ficção científica em "San Junipero", contracenam com o tema da nostalgia, que guia o enredo do episódio. A motivação das protagonistas em revisitar suas imagens tais como foram na juventude, fundamenta o argumento terapêutico da tecnologia San Junipero a partir da ideia de uma "cura" individual pela nostalgia. Esse passado, revisitado dentro do sistema, serviria aos usuários como um remédio alternativo e tecnológico aos traumas pessoais, as doenças da velhice e a proximidade da morte.

Diferente das máquinas do tempo fantasiosas, consagradas na ficção científica literária e cinematográfica, que lança os sujeitos em uma ruptura temporal para o futuro ou para o passado, a tecnologia em "San Junipero" garante uma viagem temporal pela elaboração de um tempo virtualizado pelo sistema. A iluminação em neon do bar frequentado pelos usuários do sistema, os figurinos semelhantes aos usados por protagonistas de filmes teen e as canções românticas e dançantes que sonorizam a ambientação do episódio, convertem o passado em um sentimento de nostalgia, que se manifesta através de símbolos desse passado nostálgico. 
No episódio, o tempo cronológico dessa nostalgia conduz os protagonistas e o espectador ao ano de 1987. Os "Anos 80", reproduzido no sistema e evocado pelo episódio, remete o espectador à forma com que essa década alcança o presente, não pelas fatualidades e pelos eventos históricos vividos nesse período, mas pelas imagens e sons produzidos pelas mídias televisivas e cinematográficas consolidadas nessa década. A presença do cartaz de estreia do filme Garotos Perdidos (1987) na principal rua da cidade, a juventude de San Junipero ouvindo a canção "Heaven is a Place on Earth" (1987), de Berlinda Carlisle, a presença do videogame Bubble Bobble (1986) no interior do bar, dentre outros elementos que remetem o espectador ao ano de 1987, são dispostos em cena como uma forma de preparar uma experiência nostálgica audiovisual junto às protagonistas.

Ainda que o passado nostálgico e sentimental do episódio pelos "Anos 80" se distinga de um passado factual e histórico, a "viagem temporal" realizada por Yorkie e Kelly perpassa alguns aspectos políticos e sociais relacionados à prevalência de questões da década de 1980 vividas nos Estados Unidos na década 2010. A presença dos "Anos 80" na década de 2000 e 2010, se deu predominantemente pelas produções midiáticas audiovisuais. Como nos aponta o produtor cultural Simon Reynolds em Retromania: Pop Culture's Addiction to its Own Past (2011), o início do século XXI é marcado pela "década de res" (REYNOLDS, 2011, p. 11, tradução livre7) que figuraram a nostalgia na cultura pop nos Estados Unidos: os produtos "retrô", os revivals musicais de artistas como Madonna, Michael

7 Em inglês, o autor utiliza o termo "The 'Re' Decade". 
Jackson ou The Smiths, as reprises televisivas, os remakes e as sequências de franquias consagradas no cinema nesta década, tomaram conta dessa atmosfera de "vale a pena ver e ouvir de novo" ocorrida em Hollywood e nas indústrias televisivas e musicais. A produção audiovisual converteu esse sentimento histórico em uma possibilidade de reviver o passado nas telas e nas caixas de som.

Em "San Junipero", a nostalgia cultural marca presença nas cenas e nas canções ouvidas ao longo do episódio. As referências visuais e produções cinematográficas, as canções românticas e a presença de objetos e aparelhos utilizados em 1987, reafirmam essa imagem cultural da nostalgia pelos "Anos 80" revisitada pelo século XXI. Porém, o tema da nostalgia marca não apenas a sua representação cultural. A nostalgia pelos "Anos 80" em "San Junipero" oferece uma crítica a outras representações nostálgicas que fogem o âmbito da cultura e adentram a realidade política do país no ano de 2016, marcadas pela campanha presidencial do Partido Republicano, liderada pelo empresário Donald Trump.

No slogan oficial da campanha do Partido Republicano em 2016, a manifestação de nostalgia se deu pela ideia de "reconstrução" de uma nação desviada de suas origens culturais e políticas. Sintetizada pela frase "Make America Great Again", traduzido para o português como "Faça a América grande de novo", Trump promovia-se politicamente como o candidato que seria responsável por reconduzir o país em direção aos valores perdidos de outrora que fundaram a nação estadunidense.

Dentre estes valores, perpassou no discurso de Trump a idealização do "retorno" a uma nação culturalmente pura, de 
cidadãos de origem anglo-saxã, protestante e branca. Para o republicano e seus apoiadores, a retomada dessa nação ideal só seria possível pelo isolamento dos Estados Unidos perante outras culturas, especialmente provinda das fronteiras com o México, que se manifestou politicamente como uma tentativa de separação física do país em relação ao seu vizinho latino. Tendo em vista as origens escravistas do país, a imagem desse passado que se quer reconstruir no presente, manifestou também o anseio por um período em que os cidadãos negros do país eram segregados e perseguidos. Para além do discurso, dentre os principais apoiadores do projeto de "reconstrução" nacional idealizado por Donald Trump em 2016, destaca-se o apoio majoritário de estados do sul, defensores da continuidade da escravidão durante a Guerra de Secessão (1861-1865), grupos historicamente responsáveis pela perseguição aos negros no país como a Ku Klux Klan, bem como movimentos surgidos de fóruns conservadores, supremacistas e de extrema direita na internet durante a década de 2010, como os Proud Boys, Atomwaffen Division e outros representantes da chamada "direita alternativa".

As intenções políticas de Trump e do Partido Republicano, para além de evocar o sentimento histórico de uma suposta "perda" vivida pela nação estadunidense, faz alusão à frase utilizada pela campanha política que comandou os Estados Unidos em quase toda a década de 1980. O slogan utilizado pelo ex-presidente republicano Ronald Reagan, "Let's Make America Great Again", traduzido para o português como "Vamos fazer a América grande de novo", foi reinterpretado na campanha de 2016 com a intenção de associar a imagem de Trump com as 
políticas promovidas pelo ex-presidente dos Estados Unidos. A assinatura patriota dos dois mandatos de Reagan, entre 1981 e 1989, marcadas pela implementação de medidas econômicas liberais e pautas conservadoras de costumes, alcança os anseios da direita americana no ano de 2016 como um momento simbólico de retomada dos valores originais da nação estadunidense em um passado recente.

Como nos aponta a historiadora Svetlana Boym em The Future of Nostalgia (2001), o sentimento de nostalgia, quando apropriado pelo discurso político, quase exclusivamente se atrela ao sentimento nacionalista, concebendo a nação como um "lar" compartilhado culturalmente pelos cidadãos que nela vivem. Boym observa que, a partir do século XIX, o sentimento de nostalgia foi mobilizado pelos discursos nacionalistas, através da concepção da nação como um lugar de sacrifício e glória, sendo o seu passado um tempo de sofrimento compartilhado. A condição individual da nostalgia em sua origem, tal como fora diagnosticada por Johannes Hofer em 1688, dá lugar a um sentimento transformado em pertencimento coletivo, que se debruça sobre os sofrimentos passados que transcendem as memórias individuais (2001, p. 15). Os feitos dos cidadãos e dos heróis nacionais do passado, tornamse vitórias para o presente.

Uma vez sendo uma emoção histórica que se manifesta pelo anseio - "nostos" - pelo reencontro - "algia" -, esse sentimento individual e coletivo datado do século XVII, se faz representado no discurso de Trump como o anseio por reconstruir o momento em que a nação estadunidense estivera à frente das transformações culturais e políticas do mundo ocidental. Boym entende que as 
apropriações políticas da nostalgia constituem uma tendência, a qual a historiadora define como "nostalgia restauradora" (2001, p. 41), ou seja, um sentimento pela história que prospera pela intenção de "reconstrução" do passado no presente. A historiadora associa os discursos nacionalistas que se utilizam do sentimento nostálgico pelo "lar perdido" da nação, a uma tendência de movimentos e grupos políticos nacionalistas contemporâneos e de extremadireita da virada do século XX para o século XXI (BOYM, 2001, p. 43). Essa busca pela reconstrução nacional coincide com o surgimento de teorias conspiratórias de invasão cultural de outros povos e o temor de ameaças internas e externas, vistas como potenciais "impurezas" em relação aos valores originários do país.

De forma semelhante à Trump, na década de 1980, o discurso restaurador de Reagan e do Partido Republicano promoveu a perseguição política em relação aos homossexuais, sendo essa uma das frentes das pautas morais que buscavam reconstruir os valores do país pela eliminação de supostas ameaças internas. Especialmente após a explosão da pandemia de HIV no mundo e o aumento de casos de AIDS nas grandes metrópoles dos Estados Unidos, a marginalização das comunidades homossexuais entrou na pauta política do governo de Reagan, junto à marginalização das comunidades negras e latinas do país. A proliferação da AIDS no país foi fundamental para a consolidação do discurso de "demonização" da homossexualidade, levando a comunidade médica a associar a transmissão do vírus exclusivamente às comunidades homossexuais (TROVÃO, 2010, p. 111). Essa perseguição aos gays, potencializada pela transmissão do vírus, foi apropriada pelo discurso conservador como uma pauta moral em 
defesa do núcleo familiar heterossexual, que serviria à renovação da juventude do país com base em valores tradicionais.

Em "San Junipero", o sentimento nostálgico simbolizado pelos filmes teen da década de 1980 não é por acaso. Ao longo da década de 1980, as produções cinematográficas que protagonizaram personagens da juventude estadunidense, promoviam a imagem renovada de uma geração posterior às derrotas políticas da Guerra do Vietnã, representada pelos yuppies ${ }^{8}$, que tomariam a frente do mercado financeiro de Wall Street e carregavam o espírito do liberalismo econômico que despontava no horizonte do país. Assim sendo, a juventude representada se alinhava à normatização que se buscava nas pautas conservadoras do governo.

Também neste contexto, as produções cinematográficas voltadas para o público jovem, consagradas por diretores como John Hughes, Robert Zemeckis e Steven Spielberg, de forma nostálgica, celebrava um sentimento de "retorno" ao passado representado pela década de 1950, através do cinema e da televisão (CÁNEPA; FERRARAZ, 2016, p. 175). Sendo essa a década que marca o nascimento e expansão da cultura jovem e consumista do país, consolidando a hegemonia política e cultural no eixo capitalista durante a Guerra Fria, o período de otimismo econômico e expansão demográfica causado pelo pós-guerra dos "Anos 50", foi rememorado pelas produções audiovisuais da década de 1980, lançando olhares para esse passado, visando reconstruí-lo no presente.

8 A expressão deriva da sigla abreviada de "Young Urban Professional", que em português é traduzido como "Jovem Profissional Urbano". O termo foi utilizado na década de 1980 nos Estados Unidos para designar a geração de jovens que se estabeleciam no mercado financeiro em grandes centros urbanos. 
O slogan de Trump se apropria da frase de Reagan da década de 1980 num mesmo sentido: buscar no passado aquilo que se quer construído no presente. Nesse caso, a relação entre o discurso conservador do presidenciável em 2016 e a do ex-presidente em 1980 promove uma identificação com o conservadorismo, o patriotismo, a ideia de ameaças externas e internas. Se para o eleitor estadunidense, Reagan foi capaz de dar fim à Guerra Fria, enterrar o bloco soviético, inimigo ideológico do país desde 1946, e guiar os Estados Unidos a uma ascensão econômica liberal, Trump associa esse passado aos conflitos políticos do presente: a intenção de enterrar as ameaças dos inimigos externos, como a China, a Rússia e Irã, eliminar as ameaças internas, encarnada nas populações latinas, negras e em imigrantes de países muçulmanos, ao mesmo tempo que retomar o patriotismo e a grandiloquência supostamente perdida após os dois mandatos de Barack Obama.

A partir dessa análise, podemos evidenciar que o tema da nostalgia em "San Junipero" ganha outros sentidos em relação aos usos políticos e restauradores da nostalgia no discurso presidencial em 2016. Isso se evidencia em dois momentos do episódio. O primeiro se dá em um diálogo de Kelly com Yorkie no bar da cidade. Logo após se conhecerem, Kelly ironiza a falta de autenticidade dos outros usuários em San Junipero, ao dizer que seus estilos parecem ter sido tirados de um filme. No segundo, durante a sequência de troca de roupas de Yorkie em frente a um espelho, ao se vestir como a personagem Allison Reynolds do filme O Clube dos Cinco (1985) de John Hughes, um dos cânones cinematográficos da juventude "oitentista" estadunidense, a personagem não se identifica com o visual, 
recusando-o em busca de um estilo mais autêntico. Uma vez que a imagem dessa juventude dos "Anos 80" representada nas telas dos cinemas de Hollywood estavam alinhadas às pautas morais do governo conservador de Reagan em 1980, no ano de 2016, as representações cinematográficas desse passado são como uma roupa sem autenticidade que não serve aos anseios do presente.

Dessa maneira, Owen Harris e Charlie Brooker conduzem o espectador a uma representação distinta da nostalgia pelos "Anos 80" em seu episódio, recusando as imagens dessa juventude, ao mesmo tempo contrariando o anseio pela reconstrução fiel do passado tal como ele foi marcado pela perseguição e demonização da comunidade homossexual. O protagonismo do casal Yorkie e Kelly no ano de 1987, contesta a imagem conservadora da juventude da década de 1980 tal como ela se manifestou no cinema e como se almejava alcançar na sociedade, reinterpretando o passado traumático experienciado por essa comunidade. Da mesma forma, concorre com a nostalgia política propagada nos discursos do Partido Republicano, representando esse sentimento não como uma possibilidade de reconstrução do passado, mas como uma forma de situar as transformações ocorridas na sociedade estadunidense entre 1987 e 2016.

O sistema San Junipero, nesse sentido, imerge o espectador em um tempo alternativo ao presente junto às protagonistas, aproximando as representações nostálgicas do episódio das representações dos "Anos 80" que proliferam nas mídias e na política. Não somente representa, como se apropria desse sentimento na consolidação de uma narrativa nostálgica que engloba outras produções realizadas pela Netflix. Como nos aponta 
Giulia Taurino (2019), as manifestações de nostalgia existentes na mídia contemporânea, especialmente nas plataformas de streaming, nos dizem mais sobre a indústria das mídias e as transformações ocorridas no interior dela com a expansão da Netflix, do que sobre o sentimento de nostalgia em si.

Taurino entende que a aposta em conteúdos nostálgicos parece ter sido uma das principais frentes do conteúdo realizado pela plataforma, uma vez observada, através das interações, dos engajamentos e dos algoritmos que estruturam a tecnologia da plataforma, a tendência dos espectadores de procurar em seu catálogo, conteúdos produzidos no passado e disponibilizados digitalmente. A ideia de "resgatar" do passado um conteúdo já realizado, não é uma estratégia nova na indústria das mídias. Porém, a Netflix tornou a nostalgia e o conceito de "ver de novo" um dos pilares de sua marca (TAURINO, 2019, p. 18).

De fato, o caráter "arquivista" da Netflix, que possui em seu catálogo filmes produzidos desde a década de 1960, possibilita aos espectadores acessar conteúdos veiculados na televisão e no cinema pré-digital, fazendo de seu usuário um "viajante no tempo" do audiovisual. Contudo, a nostalgia da plataforma não se limita a conduzir os usuários a explorar o passado audiovisual, mas realiza produções que tematizam esse sentimento. Séries como Stranger Things (2015), The Get Down (2016), GLOW (2017), Pose (2017) e Cobra Kai (2018), são produções seriadas que apostam no tema da nostalgia pelos "Anos 70" e "Anos 80" como suas principais características, revivendo estéticas, canções, temas e enredos consagrados no audiovisual nessas décadas, a partir de produções originais e inéditas. 
Dessa forma, como nos indica Philippe Gauthier (2019), por meio dessas produções que tematizam a nostalgia, a Netflix construiu um gênero próprio em seu catálogo, possibilitando uma espécie de "narrativa nostálgica" que engloba toda a plataforma e dialoga entre si. Em seu estudo sobre a série GLOW, série protagonizada por mulheres situada na cidade de Los Angeles em 1985, Gauthier entende o caráter histórico da nostalgia nas mídias como um "espaço cultural problemático" (GAUTHIER, 2019, p. 76), em constante competição em suas representações. Para o autor, a forma com que a nostalgia pelos "Anos 80 " é representada nessa e em outras produções da Netflix, oferece ao espectador uma visão alternativa dessa década, fortalecendo os laços entre a nostalgia e a consciência histórica. Não se trata de criar uma perspectiva falsa sobre o passado, mas reinterpretar as imagens e os sons dessa década que prevalecem nas mídias, como parte de uma redefinição política dos Estados Unidos em relação ao passado e ao presente.

Esse sentido dado à nostalgia em "San Junipero" não é um caso isolado nas produções da Netflix. O quarto episódio da terceira temporada de Black Mirror, dialoga com uma gama de outras produções inseridas nesse gênero de nostalgia inaugurado pela plataforma. Dentre essas produções que compõem a narrativa nostálgica da Netflix, podemos destacar as reinterpretações históricas das décadas de 1970 e 1980 nos Estados Unidos, investindo o passado em benefício dos anseios políticos das comunidades feministas, LGBTQ, latinas e afro-americanas, como nas séries GLOW, The Get Down e Pose. Dessa forma, diferentemente das representações nostálgicas observadas 
nas décadas de 1970 e 1980, criticadas no passado por teóricos como Marc Le Sueur (1977) e Fredric Jameson (1991) como uma tendência midiática exclusivamente conservadora e vazia de valor histórico, essas produções conduzem o espectador às reflexões sobre o aspecto histórico dessas representações nostálgicas, conduzindo questionamentos sobre o presente, tendo o passado como um "espelho".

Nesse sentido, o episódio "San Junipero" pode ser compreendido dentro dessa lógica comercial da plataforma, utilizando as estruturas narrativas da ficção científica em sua relação com o desenvolvimento tecnológico e as diferentes configurações de espaço-tempo, para tematizar a nostalgia. Porém, mais que tematizar esse sentimento em referência à década de 1980, o episódio oferece uma nova visão dos "Anos 80", alinhado à forma com que outras produções semelhantes representam essa década. A elevação do casal interracial, de mulheres jovens e homossexuais ao protagonismo, a escolha pela eutanásia de Yorkie, o temor de Kelly em submeter-se eternamente a um sistema virtual e o "final feliz" de união entre as duas protagonistas, são temas que condizem com as reivindicações de protagonismo social e político por parte da comunidade LGBT no momento de produção do episódio. Ao desenhar esse passado alternativo, o episódio subverte as imagens conservadoras dos filmes teen da década de 1980 e oferece outros caminhos à nostalgia política presente no discurso conservador do Partido Republicano na corrida eleitoral de 2016.

Em contraponto às tendências de "nostalgia restauradora", observada nos discursos políticos nacionalistas e conservadores, 
Boym estabelece a definição de "nostalgia reflexiva" como uma tendência igualmente expressa nas mídias e na política. Ao contrário da "nostalgia restauradora", a "nostalgia reflexiva" enxerga as ambivalências do passado, lidando com as dores, as ironias e o anseio pelas experiências vividas no tempo decorrido. A frustração da impossibilidade de retorno é a principal característica dessa tendência que prospera pela dor de enxergar as continuidades e as rupturas do passado em relação ao presente. Boym associa a mobilização da nostalgia reflexiva nas representações midiáticas como uma forma de denunciar a prevalência de contradições do passado, projetando uma capacidade pedagógica do passado em relação ao presente e ao que se espera do futuro.

Na trama de Yorkie e Kelly, a impossibilidade de retornar ao passado é solucionada pelo argumento tecnológico do sistema San Junipero. Portanto, a dor do anseio pelo tempo vivido, sentimento comum aos nostálgicos, se torna um remédio, uma terapia de imersão virtual capaz de sanar as necessidades do presente. Trata-se de uma inversão da própria concepção da nostalgia, originalmente entendida como uma condição da alma e do corpo em reação à saudade da terra natal, agora entendida como um sentimento libertador, capaz de romper com a moral conservadora que paralisava as protagonistas.

A partir dessa característica invertida da nostalgia no episódio e complementando a perspectiva de Boym, podemos destacar a forma com que o historiador Eduardo Ferraz Felippe, em Renovar os votos com o futuro: nostalgia e escrita da história (2017) entende a nostalgia expressa nas sociedades contemporâneas, especialmente em suas representações midiáticas e políticas. No momento de 
seu surgimento, no fim do século XVII, a nostalgia era entendida como uma condição médica que se manifestava como um apreço doloroso e desmedido pelo passado. Contudo, no século XXI, o historiador analisa que a nostalgia [...] deixou de ser entendida como o apego desmedido ao passado, como foi considerada em sua versão setecentista. Torna-se, hoje, uma resposta ao presente; por vezes, estática e imobilizadora; por outras, em permanente anseio por futuro (2017, p. 125).

Contestando o caráter pedagógico do passado, tal como se manifesta na concepção de Boym, o autor compreende que esse anseio pelo passado nostálgico tende a lidar com a incapacidade das sociedades modernas de se aprender com a história e de se projetar para um futuro próximo. Ainda assim, a proximidade entre a nostalgia e a história se dá na capacidade deste sentimento transcender o tempo histórico e buscar no passado os potenciais perdidos e o sentimento de falta pelo que não se concretizou.

Em "San Junipero", as representações dos tempos "passado" e "futuro", evidenciam essa característica da nostalgia em nosso tempo. Passado, presente e futuro convergem na trama, ao mesmo tempo evidenciando utopias passadas que não se concretizaram no presente com a manutenção de políticas que pautam a perseguição contra minorias, ao mesmo tempo que olha para o a década de 1980, que inaugurou a cultura multimidiática e audiovisual que se vive no presente, como um "lar" perdido possível de ser reinventado.

O passado alternativo de 1987, projetado às protagonistas e ao espectador no interior do sistema San Junipero e tornado 
concreto a partir de uma simulação tecnológica, manifesta em suas representações nostálgicas e futuristas a incapacidade de antever o futuro e o anseio por olhar para o passado da forma com que este poderia ter sido. Owen Harris e Charlie Brooker fogem da crítica à sociedade tecnológica, característica das narrativas de ficção científica distópica e que consagrou o escopo da série Black Mirror, buscando no desfecho otimista de "San Junipero" um antídoto nostálgico ao presente político dos Estados Unidos em 2016, ao passado conservador de 1987 e ao que se colocava no devir histórico do país com a eleição de Donald Trump.

\section{CONSIDERAÇÕES FINAIS}

Considerando as ideias abordadas e discutidas anteriormente, pode-se afirmar que a nostalgia, tal como é representada no episódio "San Junipero", compõe uma narrativa maior que pode ser encontrada em diversas outras produções que tematizam esse sentimento em seus enredos, visualidades, musicalidades e cenografia. Somado aos temas próprios da ficção científica, o episódio conduz o espectador a uma viagem temporal a 1987, remodelando a máquina do tempo conforme as tecnologias virtuais do século XXI e propondo uma imersão sentimental no passado.

Sendo o quarto episódio da terceira temporada de Black Mirror, temporada esta que marca a migração da série para a plataforma da Netflix, o episódio funciona em nossa análise como uma peça de toda a narrativa da antologia. Sua análise nos permite tirar conclusões sobre as representações das tecnologias virtuais produzidas na série, que buscam ir além do antagonismo entre a "tecnofobia" e a "tecnofilia" consagrados na ficção 
científica do século XX. Essa abordagem do episódio, menos afeita à dicotomias e oferecendo ao espectador os benefícios e os malefícios dos usos das tecnologias pelas protagonistas, fortalece o caráter crítico da série, ao mesmo tempo que põe em tela - nas diversas telas onde a série pode ser assistida - a complexidade da forma com que o início do século XXI encara a ubiquidade e a expansão da virtualização. Longe de negar ou aceitar indiscriminadamente o avanço tecnológico, Black Mirror aposta em narrativas mais abrangentes da relação entre a subjetividade e o imaginário tecnocientífico.

No momento que as protagonistas aceitam viver "felizes para sempre" dentro do sistema, Black Mirror toma as tangentes de seu escopo crítico aos usos e abusos das tecnologias digitais e virtuais da atualidade. Embora conclua de forma otimista, distinguindo este episódio de toda a ambientação distópica característica da antologia de Charlie Brooker, o episódio "San Junipero" não se cega à crítica política ao presente vivido nos Estados Unidos no ano de seu lançamento: a nostalgia política do Partido Republicano que objetivava "fazer a América grande novamente", bem como as imagens conservadoras da Hollywood dos "Anos 80", não servem às demandas políticas e as pautas sociais do presente. $\mathrm{O}$ sistema serve às protagonistas como uma terapia de imersão nostálgica de suas juventudes, oferecendo alternativas ao presente. A viagem temporal nostálgica das protagonistas serve também ao espectador, como um deslocamento temporal de fuga do presente e de alternativa aos anseios pelo futuro de 2016. 


\section{REFERÊNCIAS}

ANTUNES, Ricardo. O Privilégio da Servidão: o novo proletariado de serviços na era digital. São Paulo: Boitempo, p. 325, 2018.

BAUDRILLARD, Jean. Simulacros e simulação. Lisboa: Relógio D’Água, 1991. SAN JUNIPERO (Temporada 3, ep. 4). Black Mirror [Seriado]. Direção: Owen Harris Roterista: Charlie Brooker. Inglaterra/Estados Unidos: Netflix, 2016. (61 min.). BOYM, Svetlana. The future of nostalgia. New York: Basic, 2001. CÁNEPA, Laura L.; FERRARAZ, Rogério. A nostalgia dos anos 1950 no cinema norte-americano dos anos 1980: os casos de De volta para o futuro e Veludo azul. Significação: Revista De Cultura Audiovisual, v. 43, n. 46, p. 157-178. Disponível em: https://www.revistas.usp.br/significacao/article/view/111473. Acesso em: 8 de fev. 2021.

CASTELLS, Manuel. A sociedade em rede. 8 ed. v. 1. São Paulo: Paz e Terra, 2005. FURTADO, Paulo. Combater o Futuro: Um olhar sobre as representações "tecnofóbicas" de ciência e tecnologia na cinematografia moderna. E-topia Revista Electrónica de Estudos sobre a Utopia, n. 10, p. 4, 2009. Disponível em: http://ler.letras.up.pt/uploads/ficheiros/7521.pdf. Acesso em: 8 de fev. 2021. JAMES, Edward. Science Fiction in the Twentieth Century. Oxford: Oxford University Press, 1994.

JAMESON, Fredric. (1991). Pós-modernismo: a lógica cultural do capitalismo tardio. São Paulo: Ed. Ática, 1996.

JAMESON, Fredric. Progress versus Utopia; Or, Can We Imagine the Future? Science Fiction Studies, Utopia and Anti-Utopia, v. 9, n. 2, julho, p. 147-158, SFTH Inc, Indiana, 1982.

LE SUEUR, Marc. Theory Number Five Anatomy of Nostalgia Films: Heritagesand Methods. Journal of Popular Film 6, Londres: Routledge, n. 2, p. 187-197, 1977.

MELL, Peter., GRANCE, Timothy. The NIST Definition of Cloud Computing Gaithersburg: NSIT - U.S. Department of Commerce, p.2, 2011. Available at: https://nvlpubs.nist.gov/nistpubs/Legacy/SP/nistspecialpublication800-145. pdf. Accessed on: 8th Feb. 2020 
LÉVY, Pierra. O que é o virtual? Tradução de Paulo Neves. São Paulo, Ed. 34, 1996. LÉVY, Pierre. O que é Cibercultura?. São Paulo: Ed. 34, 1999.

REGIS, Fátima. Como a ficção científica conquistou a Atualidade. In: REGIS, Fátima. Nós, Ciborgues: tecnologias de informação e subjetividade homemmáquina. Rio de Janeiro: Programa de Pós-graduação da ECO-UFRJ, p. 227, 2002. REYNOLDS, Simon. Retromania: Pop Culture's Addiction to its Own Past. London: Faber and Faber, 2011.

TAURINO, Giulia. Exploring Nostalgic Reconfigurations in Media Franchises. In: PALLISTER, Kathryn (Org.). Netflix Nostalgia: Streaming the Past On Demand. Lexington Books. 2019.

TROVÃO, Flávio Vilas-Boas. O Exército Inútil de Robert Altman: cinema e política (1983). 2010. Tese (Doutorado em História Social) - Faculdade de Filosofia, Letras e Ciências Humanas, Universidade de São Paulo, São Paulo, 2010. 